\title{
SERUM LACTATE DEHYDROGENASE AND CREATINE KINASE DURING MARATHON TRAINING
}

\author{
A. G. RUMLEY, MSc ${ }^{*}$, A. R. PETTIGREW, MSc*, M. E. COLGAN*, R. TAYLOR, BSct†, S. GRANT, BEd, DPE***, \\ A. MANZIE, BEd, DPE $†$, I. FINDLAY, MRCPtt, H. DARGIE, MRCP + and A. ELLIOTT, PhDt† \\ *Dept. of Pathological Biochemistry, Western Infirmary, Glasgow \\ * *Institute of Physiology, University of Glasgow \\ * * Dept. of Physical Education and Recreation, University of Glasgow \\ tDept. of Physical Education, Strathclyde University, Glasgow \\ t+Cardiology Dept., Western Infirmary, Glasgow
}

\begin{abstract}
Serum total creatine kinase (CK) and the lactate dehydrogenase (LDH) isoenzymes were studied in 38 sedentary middle-aged men (aged 35-50 yrs) during a 30 week marathon training programme. Basal CK activity rose by $33 \%$ after 15 weeks but a significant rise $(27 \%)$ in LDH activity took 30 weeks to occur. Post-exercise (maximum test on a bicycle ergometer) CK and LDH activities were higher than pre-exercise levels but the increment in enzyme activity following exercise did not change. LDH1 and LDH2 isoenzyme activity increased by $2.5 \%$ and $4 \%$ of total LDH respectively while LDH3 and LDH5 decreased by $3.9 \%$ and $2.4 \%$ respectively over 30 weeks. Post marathon total CK did not correlate with finishing time at 30 mins or $30 \mathrm{hrs}$ post race. The range of CK MB isoenzyme activity at 30 mins post race was $1.8-9.8 \%$ of total CK with 11 subjects having a value above $6 \%$. The training programme appears not to have affected muscle CK and LDH release during exercise but isoenzyme distribution changes reflect the adaptations known to occur in muscle during endurance training. Unfortunately only 16 subjects were available for all the investigations, and it is these upon whom most of the data were obtained.
\end{abstract}

Key words: Creatine kinase, Lactate dehydrogenase, Isoenzymes, Marathon training.

\section{INTRODUCTION}

Previous studies in our laboratory (Rumley and Rafla, 1983) have shown that serum lactate dehydrogenase (LDH) isoenzyme distribution may be different in athletes and non-athletes. This is not surprising since it has been shown that endurance athletes have more slow twitch (ST) muscle fibres than nonathletes (Gollnick et al, 1972) and also that ST fibres have a higher proportion of the LDH, $H$ subunits than fast twitch (FT) fibres (Karlsson et al, 1974). The serum isoenzymes are released from many tissues into the circulation and in the athlete there may be a greater contribution from skeletal muscle than in non-athletes. The different muscle cell LDH isoenzyme pattern will therefore be, at least partially, reflected in the serum distribution of isoenzymes.

Increase in total serum LDH activity after exercise has been demonstrated (Rumley and Rafla, 1983; Halonen and Konttinen, 1962) and this is probably caused both by an increase in muscle cell membrane permeability which occurs as the cell becomes energy depleted and by muscle cell damage which occurs after prolonged exercise (Hikida et al, 1981). There is conflicting evidence that neither muscle cell total $\mathrm{LDH}$ nor $\mathrm{LDH}$ isoenzymes distribution changes following exercise (Karlsson et al, 1968) but the methods for measuring muscle cell total LDH may not be sensitive enough to detect the small changes that occur. Others have shown that increased oxidative capacity in both ST and FT fibres (Gollnick et al, 1972) and decreased total muscle LDH with increased H-LDH occurs following endurance training whereas high intensity interval training has no effect on total LDH or LDH isoenzyme distribution (Sjodin, 1976).

We have demonstrated previously that serum LDH isoenzyme distribution changes during prolonged exercise (Rumley and Rafla, 1983) probably due to an increased contribution from skeletal muscle.

Address for correspondence:

A. G. Rumley

Dept. of Pathological Biochemistry

Western Infirmary

GLASGOW G11 6NT
One of our aims in this study was to determine the effect of an endurance training programme on the basal serum LDH isoenzyme distribution of non-athletes. Taking account of previous studies one might expect a higher proportion of those isoenzymes which contain predominantly the $H$ subunit (LDH1 and LDH2).

Serum total creatine kinase (CK) activity increases with exercise (Rumley and Rafla, 1983) and this has been shown to be associated with intracellular adenosine triphosphate (ATP) depletion (Thompson et al, 1975). Athletic training also raises the basal serum total CK activity the increase being related to the number of miles run per day (Robinson et al, 1982). Athletic training however reduces the serum CK and LDH response to maximal exercise possibly due to increased ATP availability in trained muscle (Hunter and Critz, 1971). This training effect on CK release from muscle after exercise may affect the serum total CK activity after a marathon race. A positive correlation between marathon finishing time and serum total CK has been demonstrated with 69 runners (Stansbie et al, 1983) and a negative relationship has also been demonstrated in which those runners finishing in less than $3 \mathrm{hr} 30 \mathrm{~min}$ had higher serum total CK than those finishing later. However, the number of runners was only 15 in this study (Siegel et al, 1980).

Release of the CK MB* isoenzyme occurs aftee exercise (Robinson et al, 1982; Sylven et al, 1983; Ohman et al, 1982) and the $\mathrm{CK} M \mathrm{MB}$ content of thigh muscle as a percentage of total CK is increased more than two-fold in highly trained long distance runners (Sylven et al, 1983). CK MB has been demonstrated in red slow twitch (ST) fibres but not in white fast twitch (FT) fibres (Rosalki, 1965). Serum CK MB activity greater than $6 \%$ of total CK activity is taken to indicate pathological myocardial enzyme release (Prellwitz, 1981) but CK MB activity greater than $6 \%$ of total CK has been demonstrated in a number of athletes following exercise with no evidence for myocardial damage (Stansbie et al, 1983; Ohman et al, 1982; Young, 1984). This elevated CK MB activity may simply reflect the increased muscle cell CK MB content of trained long distance runners.

* CK MB - Creatine Kinase isoenzymes composed of $M$ (muscle) and B (brain) subunits. 
Our intention was to study the effect of a training programme on basal serum total CK and CK release from muscle cells during exercise, to determine the correlation (if any) between post-marathon serum total CK and finishing time and to measure serum CK MB isoenzyme activity postmarathon.

\section{METHODS}

The subjects studied were 38 middle-aged men ( $35-50$ years) who had been recruited through a newspaper advertisement to participate in a study of the effects of a marathon training programme on cardiological, physiological and biochemical indices of physical fitness and risk factors for coronary heart disease. These men had previously taken no regular exercise, were not being treated for any medical condition and had not run a marathon race before the study commenced.

The training programme lasted 30 weeks and increased in stages from an initial 3 runs of $20 \mathrm{~min}$ each per week (60 min/week) to a peak at 28 weeks in which there was a long run on one day of $3 \mathrm{hr}$ and on 5 other days runs of $40-90 \mathrm{~min}(8 \mathrm{hr} /$ week) with at least one day of rest per week throughout. A further 2 weeks of training at a much lower level of intensity was followed by the Glasgow marathon in week 31 .

Testing of the volunteers was carried out at weeks 0,15 and 30 and they refrained from taking exercise for $24 \mathrm{hr}$ prior to testing. At each testing stage the subject undertook a maximal exercise test on a bicycle ergometer during which the pedalling resistance was increased from 75 watts initially in steps of 25 watts at 3 min intervals until exhaustion. Expired air was collected in Douglas bags throughout for maximum oxygen uptake $\left(\mathrm{VO}_{2}\right.$ max) estimation and blood samples were taken at rest and at exhaustion, from an antecubital vein, for enzyme measure. ments. Cardiac function was monitored by electrocardiograph (ECG) throughout the exercise test. Serum total LDH and CK and LDH isoenzymes were measured on the basal samples but total LDH and CK only were mreasured on the post-exercise samples.

Blood samples were taken from each subject within $30 \mathrm{~min}$ of completing the marathon and samples from a few athletes that finished in under $3 \mathrm{hr}$ were also obtained at this time. Further blood samples were obtained from the subjects $30 \mathrm{hr}$ after the race, these and the immediate post race samples were analysed for total CK and CK MB isoenzyme activity.

Total LDH and CK activities were measured on a Cobas Bio centrifugal analyser (Roche Diagnostics, Welwyn Garden City, UK), using optimised standard methods conforming to the recommendations of the Scandinavian Committee on Enzymes (1976) and the Deutsch Gesellschaft Für Klinische Chemie (1977) and using Beckman "Spinchem" reagents (Beckman Instrument Inc., Fullerton, Ca. 92634 USA). LDH isoenzymes were separated by agarose gel electrophoresis, visualised with nitro blue tetrazolium and measured using a scanning densitometer. CK MB isoenzyme was measured using a Boehringer kit (Boehringer Corporation Ltd., Mannheim, W. Germany) which is based on immunoinhibition of the CKB moiety.

The significance of changes in enzyme activity from pre-training levels was assessed using a paired " $t$ " test.

\section{RESULTS}

Of the original 38 subjects complete data for pre- and post-exercise enzyme activities were collected for only 16 over the 30 week training period. This low figure was due to a combination of drop-out due to injury or other reasons: subjects were unable to attend on all testing occasions and there were sampling and analytical difficulties.

The maximum test at 15 and $\mathbf{3 0}$ weeks lasted significantly longer ( $p<0.01$ ) than the initial test and the maximum work load achieved was significantly ( $p<0.01$ ) higher (see Table I). A significant improvement in the measured $\mathrm{VO}_{2} \max (p=0.015)$ of $19 \%$ for the whole group between weeks 0 and 15 was found but no further improvement occurred thereafter $\left(\mathrm{VO}_{2}\right.$ max and enzyme activity results are summarised in Table II). Pre-exercise serum total LDH activity did not change significantly from week 0 to week 15 but thereafter increased significantly ( $p<0.05$ ). The post-exercise serum total LDH activity was significantly higher than the pre-exercise activity on each testing occasion $(p<0.02)$. There was an increase in the postexercise increment (post-exercise minus pre-exercise activity) in serum total LDH activity from week 0 to week 15 but this did not achieve statistical significance. There was no significant change in the post-exercise increment between week 15 and week 30 .

TABLE I

Work load and exercise time ( \pm s.d.) at each testing stage.

\begin{tabular}{lccccc}
\hline & Week 0 & Week 15 & Week 30 \\
\hline $\begin{array}{l}\text { Maximum } \\
\text { work load (watts) }\end{array}$ & $182 \pm 36$ & $208 \pm 31$ & $208 \pm 30$ \\
\hline Exercise time (min) & $21.5 \pm 3.8$ & $24.3 \pm 3.6$ & $24.5 \pm 3.5$ \\
\hline
\end{tabular}

TABLE II

Summary of $\mathrm{VO}_{2} \max$ and enzyme activities ( \pm s.d.) at each testing stage $(n=16)$.

\begin{tabular}{|c|c|c|c|c|c|c|c|}
\hline \multirow{2}{*}{$\frac{\text { Week }}{\mathrm{VO}_{2} \max (\mathrm{ml} / \mathrm{kg} / \mathrm{min})}$} & \multicolumn{2}{|c|}{0} & \multicolumn{2}{|c|}{15} & \multicolumn{3}{|c|}{30} \\
\hline & 32.4 & \pm 4.9 & 38.7 & \pm 5.2 & 38.2 & \pm & 5.0 \\
\hline Serum total LDH (u/I) & 269 & \pm 74 & 257 & \pm 68 & 342 & \pm 1 & 33 \\
\hline $\begin{array}{l}\text { Post-exercise increment } \\
\text { in total LDH }(\mathrm{u} / \mathrm{l})\end{array}$ & 57 & \pm 47 & 106 & \pm 94 & 110 & \pm 1 & 56 \\
\hline LDH1 (\% of total LDH) & 23.5 & \pm 5.0 & & & 26.0 & \pm & 4.0 \\
\hline LDH2 (\% of total LDH) & 24.4 & \pm 4.1 & & & 28.4 & \pm & 2.2 \\
\hline LDH3 (\% of total LDH) & 29.6 & \pm 3.6 & & & 25.7 & \pm & 2.3 \\
\hline LDH4 ( $\%$ of total LDH) & 8.6 & \pm 3.2 & & & 8.4 & \pm & 2.5 \\
\hline LDH5 (\% of total LDH) & 14.0 & \pm 2.5 & & & 11.6 & \pm & 2.3 \\
\hline Serum total CK (u/l) & 123 & \pm 38 & 184 & \pm 80 & 147 & \pm & 76 \\
\hline $\begin{array}{l}\text { Post exercise increment } \\
\text { in total CK }(u / 1)\end{array}$ & 26 & \pm 28 & 30 & \pm 18 & 33 & \pm & 21 \\
\hline
\end{tabular}

LDH - Lactate dehydrogenase

CK - Creatine kinase

An increase occurred in serum LDH1 isoenzyme concentration las a percentage of total LDH) from week 0 to week 30 but this was not statistically significant. Over the same period $\mathrm{LDH}_{2}$ increased significantly ( $p<0.01$ ), LDH3 decreased significantly ( $<<0.01)$, LDH4 did not change and LDH5 decreased significantly ( $p<0.05$ ). Insufficient LDH isoenzyme results were available for week 15 for valid statistical analysis because of analytical problems.

Pre-exercise serum total CK activity increased significantly (p $<$ 0.001 ) from week 0 to week 15 but did not change significantly thereafter. The post-exercise serum total CK activity was significantly ( $p<0.01$ ) higher than the pre-exercise activity at each testing stage but the post-exercise increment was not significantly different from week 0 to week 15 or from week 15 to week 30 .

The immediate post-marathon serum total CK activities in 24 subjects (Table III) did not correlate significantly with finishing time $(r=0.26)$. Nor was there a significant correlation when the results of 7 athletes who finished in under $3 \mathrm{hr}$ were included (Fig. 1). The $30 \mathrm{hr}$ post-race serum total CK activity ( 21 subjects) also failed to correlate with finishing time ( $r=0.193$ ) (Fig. 2).

TABLE III

Post-marathon serum total CK and CK MB activity ( \pm s.d.).

\begin{tabular}{lcc}
\hline Time & $\begin{array}{c}30 \text { min } \\
\text { post-race } \\
n=31^{*}\end{array}$ & $\begin{array}{c}30 \text { hours } \\
\text { post-race } \\
n=21^{*}\end{array}$ \\
\hline Serum total CK $(u / l)$ & $762 \pm 509$ & $2213 \pm$ \\
Serum CK MB (u/l) & $41 \pm 16$ & $47 \pm 52$ \\
Serum CK MB (\% of total CK) & $5.9 \pm 2.2$ & $2.1 \pm 1.1$ \\
\hline
\end{tabular}

* includes the 16 subjects upon whom the main investigation was centred

CK MB - Creatine kinase composed of M (muscle) and B (brain) subunits

CK MB isoenzyme was detectable in the 30 min post-race samples. $(41 \pm 16 \mathrm{u} / \mathrm{l}$ and in the $30 \mathrm{hr}$ samples $(47 \pm 52 \mathrm{u} / \mathrm{l})$ but the differencewas not statistically significant. However, when expressed as a percentage of total CK the CK MB isoenzyme accounted for $5.9 \%$ at $30 \mathrm{~min}$ and $2.1 \%$ at $30 \mathrm{hrs}$ and these were significantly different ( $<<0.001$ ). The range of percentage of total $\mathrm{CK}$ at $30 \mathrm{~min}$ was 1.8-9.8 with values greater than $6 \%$ in 11 of the subjects and at $30 \mathrm{hr}$ was 1.0-5.5 with no values greater than $6 \%$.

No ECG abnormality was found in any of the subjects after the race confirming that none of the subjects suffered detectable myocardial damage.

\section{DISCUSSION}

Objective assessment of improvement in cardiovascular and respiratory function as well as increased oxygen utilisation by skeletal muscle was obtained by measuring $\mathrm{VO}_{2}$ max which increased by 19\% in the group overall from week 0 to week 15 but did not change thereafter. This demonstrates that $\mathrm{VO}_{2}$ 
SERUM TOTAL

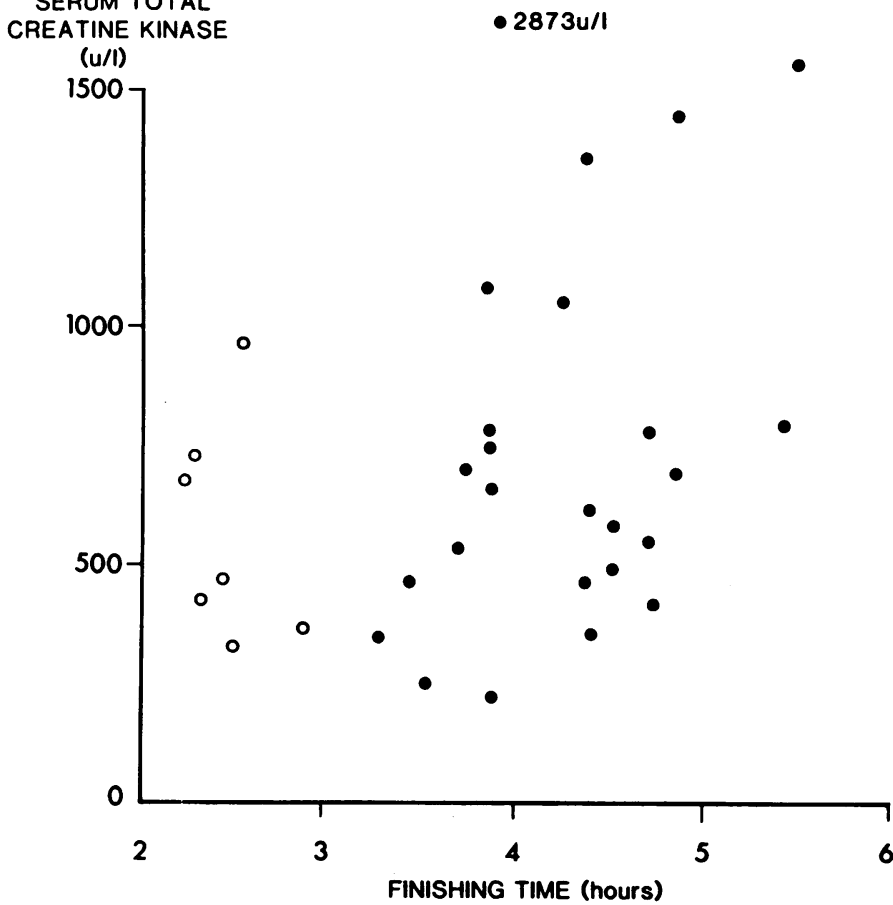

Fig. 1: Serum total creatine Kinase $C K$ and finishing time at 30 mins post-race: Correlation coefficient $r=0.26$.

- subjects under study Ohighly trained athletes

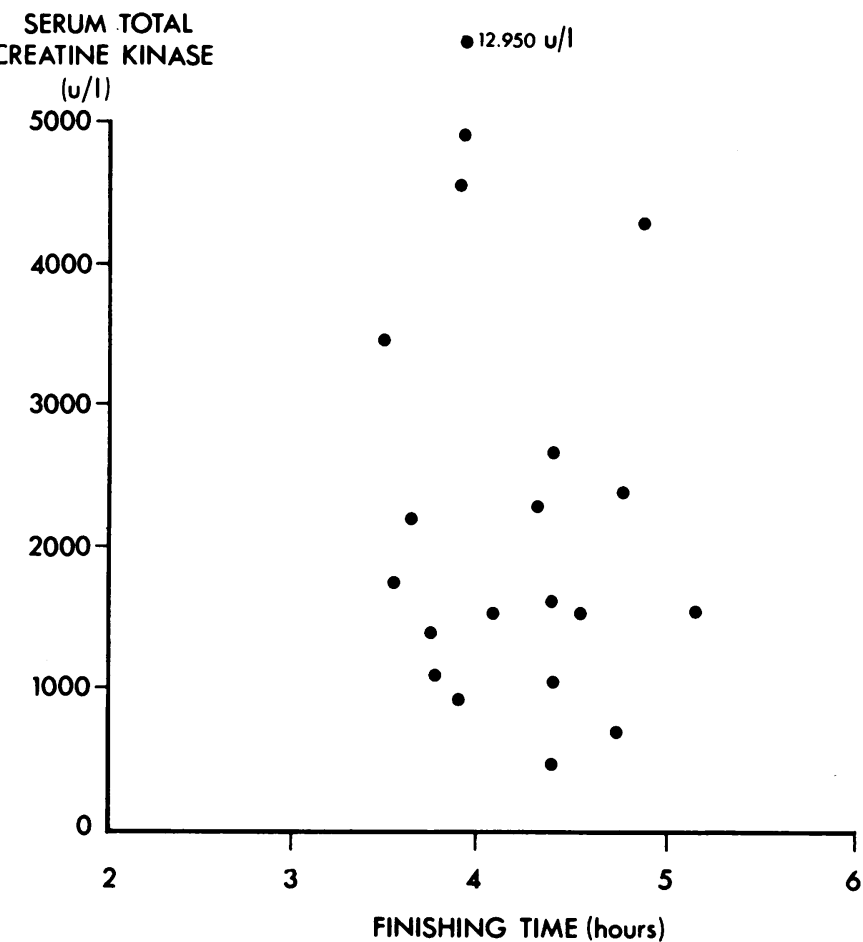

Fig. 2: Serum total creatine kinase $C K$ and finishing time at 30 hours post-race: Correlation coefficient $r=0.193$.

max increases with endurance training but that it reaches a plateau and further training does not produce a further improvement while athletic performance may continue to improve.

Our results confirm previous reports that an increase occurs in post-exercise serum total CK and LDH activities. However, in our subjects, training had no significant effect on the magnitude of the post-exercise increment. In this respect our results do not confirm those of Hunter and Critz (1971). After 15 weeks training the exercise test lasted longer and the work load achieved was higher so that although there was no decrease in enzyme release there may have been some adaptation to allow more work to be done for the same release of enzyme. A possible explanation of our results is that the mode of training (running) was different from the mode of exercise used in testing (cycling). The muscle mass used in running is not identical with the muscle mass used in cycling and therefore the enzyme release during cycling may not reflect accurately the adaptations which occur in the muscle cell induced by training. However, post-marathon serum total CK results also tend to support our post-exercise results in that performance did not correlate with CK activity even when results from trained athletes were included. This indicates that neither effectiveness of training nor inherent ability had any significant effect on post-marathon serum total CK activity. These results again, are contrary to what might be expected from the results of Hunter and Critz (1971) although it may not be possible to compare the results they obtained following a short maximum test to the post-marathon situation in which the patterns of energy expenditure, substrate utilisation and exhaustion would be very different. Our post-marathon results also conflict with published results in which both positive (Stansbie et al, 1983) and negative (Siegel et al, 1980) correlations are reported. The positive correlation was reported on $\mathbf{2 4} \mathrm{hr}$ post-race values (when the peak activity is said to occur). We measured serum total CK immediately post-race and $30 \mathrm{hr}$ post-race and found no significant correlation at either time.

Basal serum total CK and LDH activities increased with training during the first 15 weeks and then remained stable whereas the increase in LDH occurred in the second half of the training programme. This increase in basal enzyme activity is related to the number of hours run per week and reflects the continuous release of enzyme from the muscle cell into the circulation thus maintaining the increase in the measured enzyme activity which occurs during training. In the case of LDH it seems that more running hours per week are required to produce an increase in basal activity than is the case for CK. Why there is a difference in CK and LDH release from the muscle cell is not clear but the subcellular location of the two enzymes and the mechanism of their release may be different and may also be affected by the changing isoenzyme production within the cell.

Changes in the serum LDH isoenzyme distribution occurred over the $\mathbf{3 0}$ week period. Increases in LDH1 (although not statistically significant) and LDH2 with a decrease in LDH5 are consistent with release of LDH from muscle cell and appears to reflect the change in intracellular $\mathrm{LDH}$ isoenzyme distribution that has been reported during endurance training i.e. the proportion of $H$ subunits of LDH increases (Sjodin, 1976) and increased oxidative capacity occurs in both slow and fast twitch fibres (Gollnick et al, 1972). Dawson et al (1964) have postulated that the more aerobic conditions which exist in endurance trained muscle cells favour the production of $\mathrm{H}$ subunits and results in a higher proportion of LDH1 and LDH2 within the cells. We have shown that endurance training produces alterations in the serum $\mathrm{LDH}$ isoenzyme distribution of normal subjects to produce a more athletic type pattern i.e. a higher proportion of LDH isoenzymes containing $\mathrm{H}$ subunits.

Results of serum CK MB isoenzyme activity in the postmarathon samples confirm that $C K M B$ is released from skeletal muscle during this form of exercise and that the increase may exceed $6 \%$ of total CK at least in the early postrace period. This confirms previous reports that elevation of serum CK MB to greater than $6 \%$ of total CK occur in trained athletes after a marathon without evidence of myocardial damage. This no doubt reflects the physiological increase in 
CK MB content of muscle of the trained long distance runner and does not indicate pathological isoenzyme release.

The results of this study may find practical application in the use of LDH isoenzyme changes as a marker for the adequacy of aerobic training, although the large variation between individuals may make it's use difficult for any particular athlete. The absence of any effect on the magnitude of enzyme release during training and the lack of correlation of post-race CK with finishing time would appear to rule out the use of these enzyme studies either as indicators of the effectiveness of training or as predictors of performance. The post-race $C K$ and $C K M B$ results indicate that caution is required in the interpretation of the biochemical investigations of an athlete who collapses during or after a marathon race because the myocardium is not necessarily the origin of the raised enzyme activities.

During an effective marathon training regime basal serum total LDH and CK increased due to continuing release of enzyme from exercising muscle cells but the postexercise increment was not affected by training. Serum LDH isoenzyme distribution changes probably reflected the adaptations occurring within the muscle cells. Post-marathon serum total CK activity did not correlate with performance in the road race and CK MB isoenzyme activity after the race may exceed $6 \%$ of serum total $\mathrm{CK}$ in trained long distance runners.

\section{References}

Committee on Enzymes, Scandinavian Society for Clinical Chemistry and Clinical Physiology 1976. Scand.J.Clin.Lab.Invest. 36: 711.

Dawson, D. M., Goodfriend, T. L. and Kaplan, N. D., 1964 "Lactic dehydrogenases: Functions of the two types". Science 143: 929933.

Deutsch gesellschaft für Klinische chemie 1977. J.Klin.Chem.Klin. Biochem. 15: 255
Gollnick, P. D., Armstrong, B., Saubert, G. W., Piehl, K. and Saltin, B. 1972 "Enzyme activity and fibre composition in skeletal muscle of untrained and trained men". J.Appl.physiol. 33: 312-319.

Halonen, P. J. and Konttinen, A., 1962 "Effect of physical exercise on some enzymes in the serum" "Nature 193: 942-944.

Hikida, R. S., Staron, R. S., Hagerman, F. C., Sherman, W. M. and Costill, D. L., 1983 "Muscle fibre necrosis associated with human marathon runners". J.Neurol.Sci. 59: 185-203.

Hunter, J. B. and Critz, J. B., 1971 "Effect of training on plasma enzyme levels in man". J.Appl.Physiol. 31: 20-23.

Karlsson, J., Diamont, B. and Saltin, B., 1968 "LDH activity in muscle after prolonged severe exercise in man". J.Appl.Physiol. 25: 88-91.

Karlsson, J., Frith, K., Sjodin, B., Gollnick, P. D. and Saltin, B., 1974 "Distribution of LDH isoenzymes in human skeletal muscle". Scand. J.Clin.Lab. Invest. 33: 307-312.

Ohman, E. M., Teo, K. K., Johnson, A. H., Collins, P. B., Dowsett, D. G., Ennis, J. Y. and Horgen, J. H., 1982 "Abnormal cardiac enzyme responses after strenuous exercise: alternative diagnostic aids". Brit.Med.J. 285: 1523-1526.

Prellwitz, W., 1981. Creatine kinase in direct skeletal muscle damage in creatine kinase isoenzymes: Pathophysiology and clinical application. Edited by H. Lang. Publisher: Springer-Verlag, Berlin.

Robinson, D. Williams, P. T. Worthington, D. J. and Carter, T. J. N., 1982 "Raised creatine kinase activity and presence of creatine kinase MB isoenzyme after exercise." Brit.Med.J. 285: 1619-1620.

Rosalki, S. B., 1965 "Creatine phosphokinase isoenzymes". Nature 207: 414.

Rumley A. G, and Rafla N 1983 "Serum enzyme changes during 90 hours continuous basketball". Scand.J.Sports Sci. 5: 45-49.

Siegel, A. J., Silverman, L. M. and Lopez, R. E., 1980 "Creatine kinase elevations in marathon runners". Lancet p. 1505.

Sjodin. B 1976 "Lactate dehydrogenase in skeletal muscle". Acta Physiol.Scand.Suppl. 436.

Stansbie, D., Aston, J. P., Dallimore, N. S., Williams, H. M. S. and Willis, N., 1983 "Effect of exercise on plasma pyruvate kinase and creatine kinase activity". Clin.Chim.Acta 132: 127-132.

Sylven, J. C. H. Jansson, E., Brandt, S. and Kallner, A., 1983 "Specificity of cardiac enzyme in diagnosis of chest pain in marathon runners". Lancet p. 1505.

Thompson, W. H. S., Sweetin, J. C. and Hamilton, I. J. D., 1975 “ATP and muscle enzyme efflux after physical exertion". Clin.Chim.Acta 59: 241-245.

Young, A., 1984 "Plasma CK after the marathon - a diagnostic dilemma". Brit.J.Sports Med. 18: 269-272. 